\title{
Lying behaviour of horses depending on the bedding material in individual housing in boxes with or without adjacent pen
}

\author{
Janne Köster ${ }^{7}$, Gundula Hoffmann², Franz-Joseph Bockisch ${ }^{3}$, Peter Kreimeier ${ }^{4}$, Jan Reent Köster ${ }^{5}$ and Karsten Feige 6 \\ 1 Veterinary practice Köster, Kirchlinteln, Germany \\ 2 Leibniz Institute for Agricultural Engineering and Bioeconomy, Department of Engineering for Livestock Management, Potsdam, Germany \\ 3 Julius Kühn-Institute, Institute for Application Techniques in Plant Protection, Braunschweig, Germany \\ ${ }^{4}$ Thünen Institute, Institute of Organic Farming, Trenthorst, Germany \\ 5 Thünen Institute, Institute of Climate-Smart Agriculture, Braunschweig, Germany \\ ${ }^{6}$ University of Veterinary Medicine Hannover, Foundation, Clinic for Horses, Hannover, Germany
}

Summary: Horses require, as do all mammals, sufficient sleep in order to maintain their physical and psychological performance.The aim of the present study was to clarify whether different bedding material in free-stall housing and box stall housing show significant influences on the lying behaviour of horses. The influence of the housing system was investigated as well. The bedding material used was wheat straw, wood shavings and straw pellets. In the course of one year the lying behaviour of six Hanoverian mares aged 2 years was recorded by means of ALT (activity, lying time, temperature) pedometers and video recordings (continuous sampling). At the same time three horses were housed in a free-stall housing system (box with adjacent pen) and three horses in closed single boxes. The total recumbency time, sternal recumbency, lateral recumbency, the number of lying occurrences, as well as the usage of the partly available pen were examined at night (18:00-06:00). When considering the total recumbency time in the box (without consideration of the housing system) a significantly longer recumbency time was detected when using wood shavings $(211.56 \pm 69.87 \mathrm{~min} / \mathrm{night})$ in comparison to straw pellets (177.34 $\pm 98.87 \mathrm{~min} / \mathrm{night})$. On wheat straw the total recumbency time in the box was $200.92 \pm 86.32 \mathrm{~min} / \mathrm{night}$. When considering the housing systems (without taking the bedding materials into account) $100 \%$ of the recumbency time in the box stall housing system occurred in the box, inevitably due to the experimental set-up $(235.56 \pm 55.82 \mathrm{~min} / \mathrm{night})$. In the free-stall housing sysem the total recumbency time in the box and pen was significantly lower with $204.44 \pm 63.43 \mathrm{~min} / \mathrm{night}$ (recumbency time in the box: $158.00 \pm 94.62 \mathrm{~min} / \mathrm{night} ; 77 \%$ ). The recumbency time varied depending on the bedding material as well as the housing system. On the various bedding materials (wheat straw: $243.77 \pm 50.08 \mathrm{~min} / \mathrm{night}$; wood shavings: $233.02 \pm 58.92 \mathrm{~min} / \mathrm{night}$; straw pellets: $229.67 \pm 57.99 \mathrm{~min} / \mathrm{night}$ ) the total recumbency time in the box stall housing system showed no significant differences. In the free-stall housing system in comparison the total recumbency time for each bedding material (wheat straw: $157.48 \pm 93.64 \mathrm{~min} / \mathrm{night;}$ wood shavings: $190.7 \pm 73.67 \mathrm{~min} / \mathrm{night}$; straw pellets: $126.46 \pm 104.01 \mathrm{~min} / \mathrm{night}$ ) was significantly lower than in the box stall housing system. In comparison with the other bedding materials the wood shavings in the free-stall housing system partly showed a significantly longer recumbency time in the box. The use of straw pellets resulted in a longer recumbency time and a higher number of lying occurrences in the pen (free-stall housing system) in comparison to wood shavings and wheat straw. In conclusion, horses kept in single boxes with adjacent sandy pen, prefer wheat straw or wood shavings in the box as opposed to straw pellets. The total recumbency time of horses housed in box stall housing was longer on all bedding materials than in free-stall housing. However, none of the used bedding materials shortened or lengthened the total recumbency time of the horses. Therefore, all examined bedding materials can be used when keeping horses even if wheat straw or wood shavings are preferable to the use of straw pellets with regards to the lying behaviour.

Keywords: horse keeping, bedding material, lying behaviour, pen keeping, behaviour, horse, equine welfare

Citation: Köster J., Hoffmann G., Bockisch J.-J., Kreimeier P., Köster J. R., Feige K. (2017) Lying behaviour of horses depending on the bedding material in individual housing in boxes with or without adjacent pen. Pferdeheilkunde 33, 43-51; DOI 10.21836/PEM20170106

Correspondence: Gundula Hoffmann, Leibniz Institute for Agricultural Engineering and Bioeconomy (ATB), Department of Engineering for Livestock Management, Max-Eyth-Allee 100, 14469 Potsdam, Germany; e-mail: ghoffmann@atb-potsdam.de

\section{Introduction}

Horses require, as do all mammals, sufficient sleep in order to maintain their physical and psychological performance. As part of polyphasic sleep in horses the wakefulness phase, NON-REM-sleep and REM-sleep, alternate cyclically. The durations of the individual sleep stages seem to be very constant between the nights (observed over four consecutive nights). The REM-sleep, which is necessary to end a sleeping cycle, is only possible in horses in a lying position (Wöhr and Erhard 2006, Kalus 2014). Should the horse be prevented from doing so, a sleep deficit of paradoxical sleep (PS) occurs at any rate (Daillaire 1986). PS, due to the typical rapid eye movement behind closed eyelids is also referred to as REM- sleep (rapid eye movement) (Houpt 2005). According to Crowell-Davis (1994) this is responsible for the psychological well-being of horses. Furthermore, lying behaviour can be used as welfare indicator for domestic animals (Chaplin and Gretgrix 2010).

The length of sleep and the quality thereof are affected by various external influences. Two important aspects are the underground and the environment which are available for sleeping (Zeeb 1998; Zeitler-Feicht 2013). According to Schäfer (1993) horses prefer a dry surface as a sleeping place. Furthermore, he believes that the softness of the lying place also plays a certain role for horses (Schäfer 1993). This was also mentioned in a study of Zeitler-Feicht and Muggen- 
thaler (2013) with horses in a group housing system, who preferred significantly an area with shavings for lying down and as place of residence than rubber bedding mats. This was confirmed by Baumgartner et al. (2015), who found out that the daily total lying time per horse was significantly longer on shavings than on rubber mats with shavings covered. Factors such as depth, softness, texture, smell and insulating properties of the bedding material also influence the lying behaviour of horses (Rieman Pedersen et al. 2004). A clean, dry and malleable lying area should always be available for horses (BMELV, 2009).

The environment in the form of housing system also has a significant influence on the lying behaviour of horses. Results of examinations in Lower Saxonian equestrian housing systems showed that from a total of 2,147 horses $94 \%$ were housed in box stalls without an adjacent pen (Korries 2003). A study including 46 horse barns in Schleswig-Holstein which kept horses came to similar results. Stabling in box stalls prevailed in this study in $96 \%$ of the cases (Petersen et al. 2004). When horses are housed alone, feed is available ad libitum and the animals do not have to go any distance to a water source, the horses spend more time in a lying position (Fader and Sambraus 2004). In a study by Kiley-Worthington (1989, cited in Zeitler-Feicht 2001) a lying period of $10 \%$ of the time budget of horses could be ascertained in loose-housing on straw with hay being available ad libitum, while in the case of strawless box stall housing with rationed hay $16 \%$ of the time budget was given over to lying. In contrast, a study of Chaplin and Gretgrix (2010) with eight horses showed no significant affect of the housing conditions (paddock, fully stabled, partly stabled or yard) on the total time spent lying.

Hereby, no precise statement can be made, however, concerning the influence of the three respective variables (housing form, bedding material and amount of hay available). In the present study the influences of bedding materials and the housing system were considered separately as well as together so as to make precise statements concerning the influence of individual factors on the lying behaviour.

\section{Material and Methods}

The examination of lying behaviour took place in the horse stable of the Institute for Production Engineering and Building Research of the Federal Agricultural Research Centre (FAL) (now known as Thünen Institute (TI) Braunschweig) during one year. In the experiment six 2-year-old Hanoverian mares were used. The mares were housed in six individual box stalls. Each of the boxes was $12 \mathrm{~m}^{2}$ large $(3 \mathrm{~m} \times 4 \mathrm{~m})$ and had a door to the stable lane as well as a door to one of the three adjacent pens (Fig. 1). Due to the experimental set-up regular alternation between the free-stall housing and box stall housing system was possible. This changing of the housing system was able to occur by opening and closing of the corresponding pen doors so that the horses could continue to be kept in their usual box. The adjacent pen measured $108 \mathrm{~m}^{2}$, consisting of a tiled $\left(18 \mathrm{~m}^{2}\right)$ and a sand covered area $\left(90 \mathrm{~m}^{2}\right.$, washed sand). This was always made available to those horses in the free-stall housing. As only three pens were available for the individual housing simulataneously three mares were housed in box stall housing and three in box stall housing with an adjacent pen.

The bedding material used was wheat straw (manufactured by a farmer from the region of Braunschweig, Germany), wood shavings (company Goldspan, Göppingen, Germany) as well as Bioroll ${ }^{\circledR}$ straw pellets (company Heros, Drognitz, Germany) which were mostly or completely disintegrated at the time of data collection. In a preliminary test a bedding management plan was tested and decided upon which was kept for the entire experiment (Tab. 1). All boxes were completely mucked out and littered with new bedding after six weeks. An automatic feeder for hay and concentrated feed, respectively, was part of a standardised daily routine. The time-controlled roughage automatic feeders guaranteed the animals access to hay at 04:30, 14:00 and 20:00 for two hours at a time (up to $13 \mathrm{~kg}$ was offered daily). The feeding of concentrated feed was also time-controlled. At 07:00, 13:00 and 18:30 initially 250 grammes of unbruised oats were released from

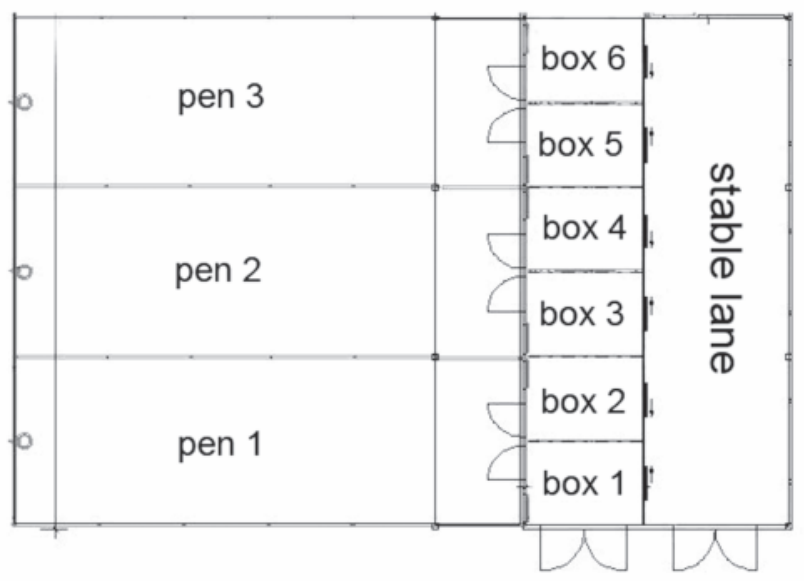

Fig. 1 Ground plan of the research stable at the Institute for Production Engineering and Building Research of the FAL Braunschweig (now Thünen Institute). | Grundriss des Versuchsstalls des Instituts für Betriebstechnik und Bauforschung der FAL Braunschweig (jetzt Thünen-Institut)

\begin{tabular}{lll}
\hline $\begin{array}{l}\text { Tab. } 1 \\
\text { Pflegemaßnahmen bei Einsatz der unterschiedlichen Einstreumaterialien im Versuch }\end{array}$ & Overview of the amount and care of the bedding materials used in this study. & Übersicht über die Einstreumengen und \\
\hline bedding material & amount of material per box* & maintenance process \\
\hline wheat straw & $\begin{array}{l}\text { at start: as much as necessary }(\varnothing 250 \mathrm{~kg} \text { each box }) \\
\text { routine: as much as necessary }(\varnothing 17 \mathrm{~kg} / \text { day })\end{array}$ & $\begin{array}{l}\text { just smoothing the surface of the bedding material } \\
\text { without removal of excrements and wet spots }\end{array}$ \\
\hline wood shavings & $\begin{array}{l}\text { at start: four bales ( } 600 \mathrm{l} \text { each) } \\
\text { routine: weekly, one bale at a time }\end{array}$ & daily removal of excrements and wet spots \\
\hline straw pellets & $\begin{array}{l}\text { at start: } 250 \mathrm{~kg} \\
\text { routine: weekly, } 30-50 \mathrm{~kg}\end{array}$ & daily removal of excrements and wet spots \\
\hline$*$ all amounts of bedding materials were measured gravimetrically &
\end{tabular}


the automatic feeder, the quantity being adjusted during the course of the experiment to the requirements due to a growth span in the horses. Additionally, the horses received 50 grammes of mineral feed ("horse vital plus", company Heinrich Eggersmann, Rinteln, Germany) daily. The stable work took place in the period between 06:00 and 12:00. During this time the mares were on the adjacent pens in groups of two and from circa 10:00-12:00 all six horses together in an outdoor paddock $(0.25 \mathrm{ha})$ near to the barn. Due to this time, which the horses spend together with at least one other horse, it was ensured that the horses could act out their social behaviour. From midday no more routine work was carried out in the stables. To compensate for external influences (e.g. temperature) all bedding materials were used parallel to one another in two boxes (free-stall and box stall ones, respectively). By changing the housing system and the bedding materials which were used in rotation for each experimental timepoint, data for all bedding materials were available in both housing systems (Tab. 2).

The data acquisition was made by the use of ALT (activity, lying time, termperature) pedometers (engineering office Holz, Falkenhagen, Germany) as well as video recordings. In order to establish the total recumbency time the mares wore an ALT-pedometer on one of their forelegs on workdays. Video recording was done during the entire examination period. Only video recordings and data from the ALT-pedometer from nights (18:00-06:00) of workdays were used in the investigation to avoid any external influences of the day. The three horse pens were monitored with a coloured low-light camera (Ganzu ZC-Y 20 PH with $2.6 \mathrm{~mm} / \mathrm{Fl}$,0 eneo DC Control lens, CBC Group, Japan) and for every two boxes a coloured camera (Exwave HAD; SSC-DC 50 AP / 54 AP / 58 AP with a 2.7-8mm/F:1:1.0 automatic iris VariVocal lens with a chip size of $1 / 3$ inches, Sony, Japan) was used. The pictures of the four cameras were bundled with the aid of a multiplexer (Ganz DPLEX-16-ECO, CBC-Group, Japan). In order to be able to capture the nocturnal video recordings of the activities of the horses, the horse barn was illuminated inside and outside. Each box was equipped with emergency lighting which was automatically controlled by a twilight sensor. Depending on the location the brightness in the boxes amounted to a maximum of 8.3 lux (measured with a T-10 luxmeter, Minolta, Japan). Evaluation of the video data was carried out by continuous sampling and the use of the Interact software (version 8.4.4, Mangold, Arnstorf, Germany) which enabled the activities of several horses to be captured at any one time.

Tab. 2 Overview of the circulation of the used bedding materials in the two different housing systems. | Übersicht über die Zirkulation der eingesetzten Einstreumaterialien in den beiden untersuchten Einzelhaltungssystemen

\begin{tabular}{|c|c|c|c|c|c|c|c|}
\hline \multirow{6}{*}{ 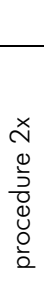 } & \multirow{3}{*}{$\begin{array}{c}\text { version } 1 \\
(2 \times 3 \text { weeks })\end{array}$} & \multicolumn{2}{|c|}{ box 1 \& 2} & \multicolumn{2}{|c|}{ box $3 \& 4$} & \multicolumn{2}{|c|}{ box $5 \& 6$} \\
\hline & & straw & straw & pellets & pellets & shavings & shavings \\
\hline & & straw & straw & pellets & pellets & shavings & shavings \\
\hline & version 2 & shavings & shavings & straw & straw & pellets & pellets \\
\hline & ( 2 x 3 weeks) & shavings & shavings & straw & straw & pellets & pellets \\
\hline & version 3 & pellets & pellets & shavings & shavings & straw & straw \\
\hline & ( 2 × 3 weeks) & pellets & pellets & shavings & shavings & straw & straw \\
\hline
\end{tabular}

Straw $=$ wheat straw, pellets $=$ straw pellets, shavings $=$ wood shavings, highlighted grey $=$ box stall housing without pen, not highlighted $=$ box stall housing with pen

Tab. 3 Overview of the investigated parameters and the analysed data per housing system. | Übersicht über die untersuchten Parameter und die analysierten Daten je Haltungssystem

\begin{tabular}{|c|c|c|c|}
\hline parameter analysed & Housing system & data acquisition in the box & data acquisition in the pen \\
\hline \multirow{2}{*}{ total recumbency time location-independent } & box with pen & $x$ & $x$ \\
\hline & box without pen & $x$ & - \\
\hline \multirow{2}{*}{ total recumbency time in the box } & box with pen & $x$ & - \\
\hline & box without pen & $x$ & - \\
\hline \multirow{2}{*}{ total recumbency time in the pen } & box with pen & - & $x$ \\
\hline & box without pen & - & - \\
\hline \multirow{2}{*}{ sternal recumbency in the box } & box with pen & $x$ & - \\
\hline & box without pen & $x$ & - \\
\hline \multirow{2}{*}{ lateral recumbency in the box } & box with pen & $x$ & - \\
\hline & box without pen & $x$ & - \\
\hline \multirow{2}{*}{ number of lying down occurrences } & box with pen & $x$ & $x$ \\
\hline & box without pen & $x$ & - \\
\hline \multirow{2}{*}{ number of lying down occurrences in the box } & box with pen & $x$ & - \\
\hline & box without pen & $x$ & - \\
\hline \multirow{2}{*}{ number of lying down occurrences in the pen } & box with pen & - & $x$ \\
\hline & box without pen & - & - \\
\hline
\end{tabular}


Six nights per bedding material and housing system were selected and analysed per video, six further nights were used to additionally determine the total recumbency time with the ALT-pedometers. Thus, after deduction of non-analysable material a total of 5124 hours of observation of individual animals could be used to determine the total recumbency period, of which 2532 hours were video material. On the one hand, the bedding materials were compared among each other in the same housing system and on the other hand the influence of the housing system when using the same bedding material was analysed. The recumbency time was examined at various locations in the respective housing system, as well as the lying positions and the use of the adjacent pen by the horses (Tab. 3).

The evaluation of the collected data was carried out with the statistical software SAS (version 9.0, SAS Institute Inc., Cary, North Carolina, USA). Due to the experimental design no

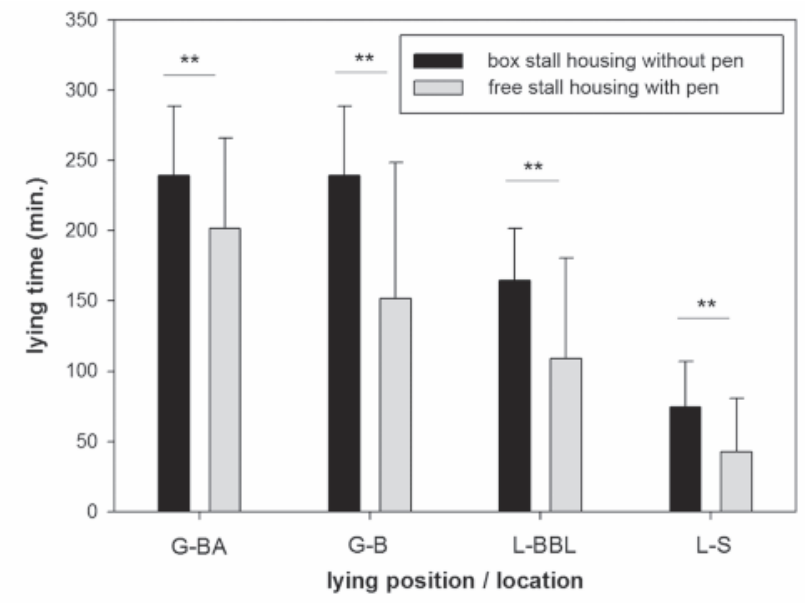

Fig. 2 Average lying time per horse and night (18:00 to 06:00) in the two housing systems (with / without pens; results of the video surveillance). G-BA=total lying time in the stall and in the pen, $\mathrm{G}-\mathrm{B}=$ total lying time in the stall, $\mathrm{L}-\mathrm{BBL}=$ time in sternal recumbency, $L-S=$ time in lateral recumbency; $P \leq 0.05$ : significant $\left({ }^{*}\right)$, $\mathrm{P} \leq 0.01$ : highly significant $\left({ }^{* *}\right), \mathrm{P} \leq 0.001$ : greatly significant $\left({ }^{* *}\right)$ Mittlere Liegedaver im Haltungssystemvergleich proPferd und Nacht (18:00 bis 6:00 Uhr; Ergebnisse der Videoauswertung). $G-B A=$ Gesamtliegedaver in Box und Auslaut, G-B= Gesamtliegedaver in der Box, L-BBL = Liegedaver in Brust-Bauch-Lage, L-S = Liegedaver in Seitenlage
Gaussian distribution of the observed parameters was to be expected. Therefore, the data were analysed with the non-parametric Wilcoxon rank-sum test (Wilcoxon, 1945) in the SAS procedure PROC NPARIWAY (Statement: ANOVA WILCO$X O N)$. The $p$-values of the individual tests were adjusted with the help of the Bonferroni-Holm procedure (Holm, 1979) to neutralise the cumulation of alpha error by multiple pairwise comparisons. In order to classify the significance level three different significance levels were considered $(p>0.05=$ not significant (n.s.) ; $p<0.05=$ significant $\left({ }^{*}\right) ; p<0.01=$ highly significant $\left({ }^{* *}\right) ; p<0.001=$ greatly significant $(* * *)$.

\section{Results}

Length of recumbency time differentiated according to bedding material

During the experiment the total length of the location-independent recumbency time was between 0 and $341 \mathrm{~min}$ per investigated night (twelve hours) and horse. The mean amounted to $219.9 \pm 61.7 \mathrm{~min}$ per night and horse. The different bedding materials had, without consideration of the housing system, no significant influence on the total length of recumbency time in any location. However, when assessing the total length of recumbency time in the boxes (without consideration of the housing system) a significantly longer length of recumbency time could be detected when using wood shavings (211.56 $\pm 69.87 \mathrm{~min} /$ night) in comparison to the straw pellets $(177.34 \pm 98.87 \mathrm{~min} / \mathrm{night})$. On wheat straw the total recumbency time in the box amounted to $200.92 \pm 86.32 \mathrm{~min} / \mathrm{night}$. The sternal recumbency time in the box as well as that in lateral recumbency in the box when comparing the three bedding materials showed no significant differences.

Recumbency time differentiated according to housing system

When considering the housing systems (without any consideration of the bedding material) $100 \%$ of the recumbency time in the box stall housing inevitably took place in the box due to the experimental set-up $(235.56 \pm 55.82 \mathrm{~min} / \mathrm{night})$. In the free-stall housing system the total recumbency time (total recumbency time in the box and pen: $204.44 \pm 63.43$, total

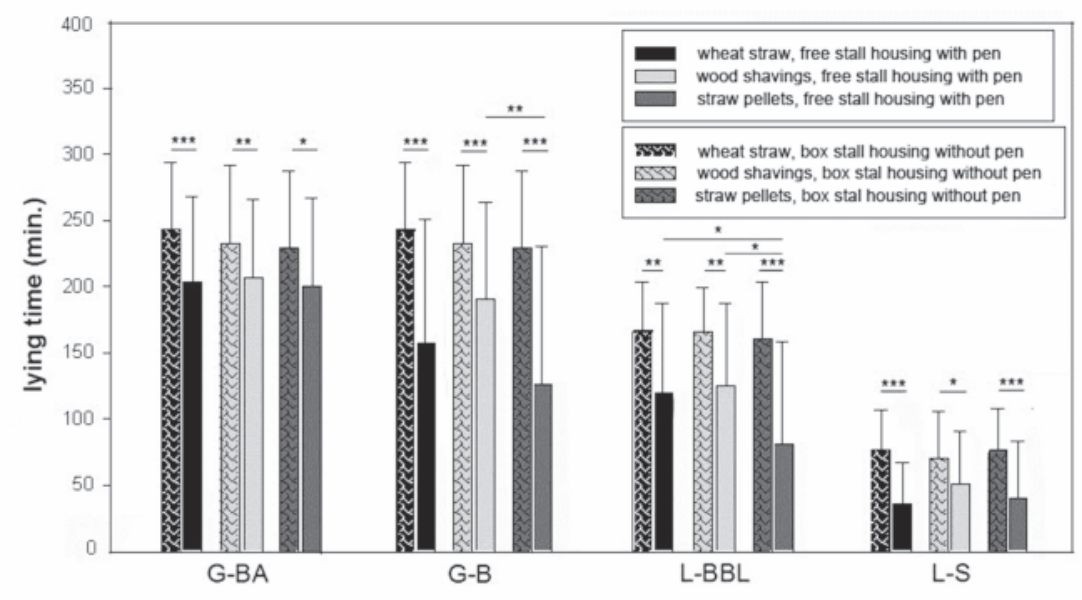

lying position / location
Fig. 3 Average lying time per horse and night (18:00 to 06:00) in different lying positions under different bedding (straw, wood shavings, straw pellets) and housing (with/without pen) conditions, $n=427$ (sternal and lateral recumbency were only measured by the video surveillance system, $n=216) ; G$ $\mathrm{BA}=$ total lying time in the box and in the pen, $\mathrm{G}$ $B=$ total lying time in the box, $L-B B L=$ time in sternal recumbency, $L-S=$ time in lateral recumbency; $P \leq 0.05$ : significant $\left({ }^{*}\right), P \leq 0.01$ : highly significant $\left({ }^{* *}\right)$, $\mathrm{P} \leq 0.001$ : greatly significant $\left({ }^{* * *}\right)$

Mittlere Liegedauer pro Pferd und Nacht (18:00 bis 6:00 Uhr) in unterschiedlichen Liegepositionen und Haltungssystemen (mit/ohne Auslauf) auf den unterschiedlichen Einstreumaterialien (Weizenstroh, Hobelspäne, Strohpellets), $n=427$ (Brust-Bauch- und Seitenlage ausschließlich durch Videoauswertung erfasst, $n=216) ; G$ $B A=$ Gesamtliegedaver Box und Auslauf, G$B=$ Gesamtliegedaver in der Box, L-BBL = Liegedaver in Brust-Bauchlage, L-S = Liegedaver in Seitenlage 
recumbency time in the box: $158.00 \pm 94.62$ ) was significantly lower (Fig. 2).

Recumbency time differentiated according to bedding material as well as housing system

The total recumbency time in the box stall housing varied between $229.67 \pm 57.99 \mathrm{~min} / \mathrm{night}$ on straw pellets and $243.77 \pm 50.08 \mathrm{~min} / \mathrm{night}$ on wheat straw and indicated no significant differences (Fig. 3). In comparison, in the freestallhousing system the total recumbency time for each bedding material was significantly lower than in the box stall hou-

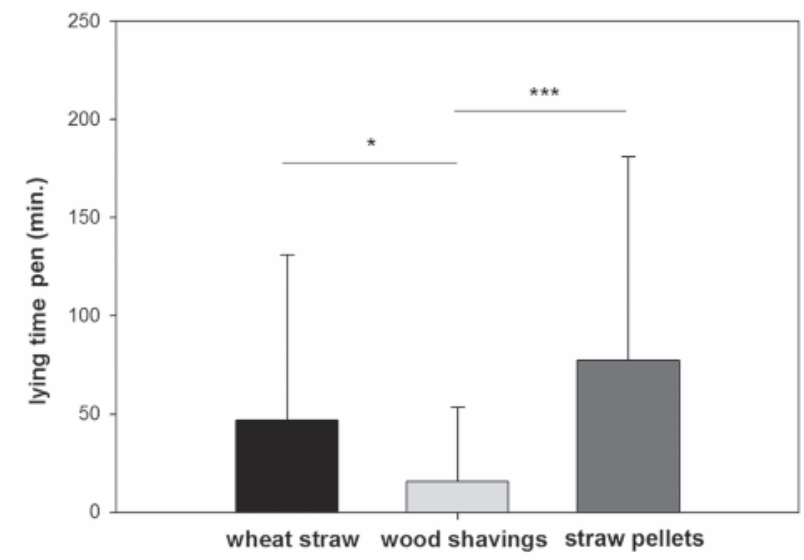

Fig. 4 Average lying time per horse and night (18:00 to 06:00) in the pen while using different bedding materials (straw, wood shavings, straw pellets) in the housings (results of the free-stall housing system), $\mathrm{n}=215 ; \mathrm{P} \leq 0.05$ : significant $\left({ }^{*}\right), \mathrm{P} \leq 0.01$ : highly significant $\left({ }^{* *}\right), \mathrm{P} \leq 0.001$ : greatly significant $\left({ }^{* * *}\right)$

Mittlere Liegedaver je Pferd und Nacht (18:00 bis 6:00 Uhr) auf dem Auslauf bei Einsatz unterschiedlicher Einstreumaterialien (Weizenstroh, Hobelspäne, Strohpellets) in der Box (Daten des Einzelboxenhaltungssystems mit Auslauf), $n=215$

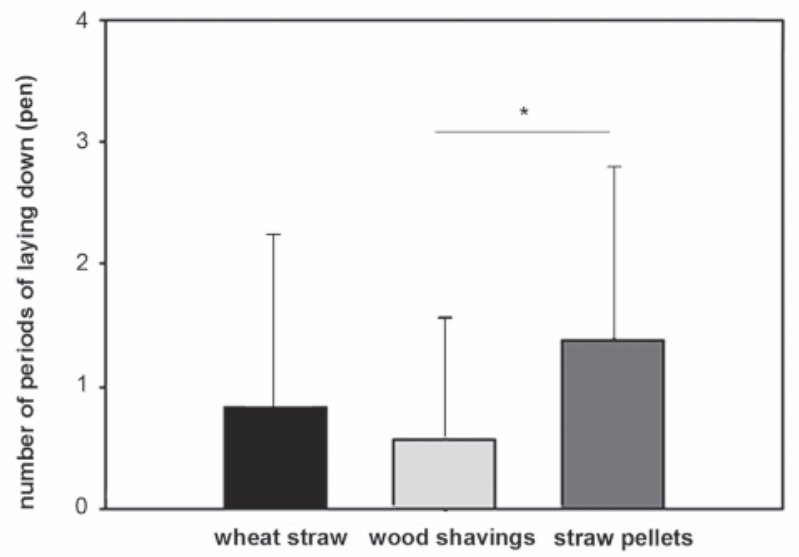

Fig. 5 Average number of lying down occurrences per horse and night (18:00 to 06:00) in the pen while using the different bedding materials (straw, wood shavings, straw pellets) in the box (results of the free-stall housing system), $\mathrm{n}=215 ; \mathrm{P} \leq 0.05$ : significant $\left({ }^{*}\right)$, $\mathrm{P} \leq 0.01$ : highly significant $\left({ }^{* *}\right), \mathrm{P} \leq 0.001$ : greatly significant $\left.{ }^{* * *}\right)$ Mittlere Anzahl an Liegevorgängen je Pferd und Nacht 18:00 bis 6:00 Uhr) auf dem Auslauf bei Einsatz unterschiedlicher Einstreumaterialien (Weizenstroh, Hobelspäne, Strohpellets) in der Box (Daten des Einzelboxenhaltungssystems mit Auslauf), $n=215$ sing. Additionally, in the free-stall housing system on the wood shavings in comparison to other bedding materials the recumbency time in the box was longer in sternal recumbency and in lateral recumbency (Fig. 3).

\section{Analysis of usage of horse pen}

The analysis of the horse-pen usage (free-stall housing system) when comparing the box bedding resulted in a longer recumbency time in the horse-pen (Fig. 4) as well as a higher number of lying occurrences in the horse-pen (Fig. 5) by the use of straw pellets in comparison with wood shavings and wheat straw.

\section{Discussion}

For humans sleep is an important prerequisite for the functional capability of the brain as well as for further processes in the body. Qualitatively good sleep of sufficient length is therefore of utmost importance (Kunz 2006). The length and quality of sleep of horses are affected by many influences. Significant influencing factors are the available underground and environment (Zeeb 1998). By domesticated horses these factors are reflected, above all, by the type of bedding material and housing system.

Attention was paid to a preferably high homogeneity in the experimental group when selecting the horses for the present investigation. Those horses which were all deemed as being healthy in the first medical examination were circa 20-monthold Hanoverian mares at the time of the first day of experiment. Using same-sex horses is sensible particularly when comparing bedding materials as there is a characteristic moisture distribution in the boxes for the respective gender. Geldings and stallions urinate in a single housing system in the centre which is anatomically conditioned or within a smaller radius around the centre, while mares urinate in the peripheral areas of the box. Hereby, geldings and stallions offer more unfavourable conditions than mares (Ubbejans 1981). Additionally, in previous investigations differences between the recumbency time of stallions and mares of Polish primitive horses were seen, whereby stallions spent $2.4 \%$ and mares $3.6 \%$ of the day lying (Kownaki et al. 1978).

The recumbency time is not due to the degree of tiredness, but when remaining in the stable also to the lack of outside influences (Steinhart 1937). Dallaire (1986) also confirmed that the amount of environmental stimuli at hand can also influence the sleeping behaviour of horses. For these reasons in the present study consistent management of the boxes was carried out. Besides, the movement opportunities of the horses were time-controlled. Only the personnel had access to the stable.

As wakefulness of horses can not be easily differentiated from that of sleep only by simply observing the animals (Dallaire 1986), in this experiment the recumbency behaviour and not the resting behaviour was investigated. Hassenberg (2005) also suggests that the differentiation between the terms resting and sleep should be taken with caution when the animals are only visually observed and their neurophysiologi- 
cal condition is unknown. By means of the implemented examination techniques the total recumbency time, the sternal recumbency and lateral recumbency times were certainly differentiated and used in the evaluation.

In the present study, significant longer total recumbency times in boxes littered with wood shavings could be observed in comparison to straw pellet bedding (by simultaneous offer of a horse-pen). Werhahn (2009) conducted a similar study in which the influence of straw pellets, straw and wood shavings as bedding material on horses in individual stables was investigated. She noticed a significantly longer total recumbency time on straw compared to straw pellets. As a percentage $26 \%$ of the investigated time was spent in recumbency on straw pellets, while $28 \%$ of the time was spent on straw, with $27 \%$ of the time on wood shavings. In the present study, no significant difference could be noticed between the total recumbency time of the mares on straw and wood shavings. This result is also reflected in an investigation by Hunter and Houpt (1989), which was unable to determine any significant differences whatsoever in the total recumbency time between straw and wood shavings in a choice experiment with eleven Shetland ponies. Another study about the effects of bedding material on the lying behaviour in stabled horses described that there was no significant difference among beddings (straw, sawdust, coconut husk, coconut fibre) in sternal and lateral lying, except between sawdust and coconut husk where the total duration of lateral lying was greater when husk was used as bedding (Ninomiya et al. 2008).

In her investigations Werhahn (2009) identified a highly significant influence of different bedding materials on the lying behaviour of individual horses, whereby the heterogeneity of horses ( $n=6 ; 2$ mares each with one foal, 2 riding horses) complicated the interpretation of the observed differences.

Riemann Pedersen et al. (2004) were also able to register no significant differences in the total recumbency time in an experiment in which the recumbency time on straw was compared with that on wood shavings. In contrast to the present study, they mention, however, a three-fold longer lateral recumbency time on straw than on wood shavings and point out that the reduced time in lateral recumbeny on wood shavings could negatively influence the well-being and performance of horses. The present study, as well as one by Bachhausen (2008) accounted for no significant differences between straw, wood shavings and straw pellets regarding the lying time in lateral recumbency. A possible cause for the different results as regards the lying positions could be the used experimental set-up of Riemann Pedersen et al. (2004), in which only 2 nights were investigated and moreover different horses were used on the different bedding materials. Furthermore, the horses in the experiment of Riemann Pedersen et al. (2004) were covered with a horse blanket which prevented direct contact between the horse and bedding material and which through its insulating and cushioning properties influenced the effect of the bedding materials on the lying horse. Unanimously all invesigations (Hunter and Houpt 1989, Riemann Pedersen et al. 2004, Bachhausen 2008, Ninomiya et al. 2008, Wehrhahn 2009) including the results in the present study state that the bedding materials straw, wood shavings and straw pellets are suitable for littering horse boxes.
Alongside the preference for wood shavings and wheat straw as opposed to straw pellets, in the present study a greatly significantly longer recumbency time could be noticed in the box stall compared with a box stall with an adjacent horse-pen. Glade (1986) had similar results in a study in which lying occurrences were compared in free-stall housing and box stall housing systems. While the total number of recumbency periods was the same in both housing systems, the recumbency length in a box stall was double as long. The differing fraction of the recumbency length of the time budget of the horses depending on the housing system can, among other things, be explained by the fact that horses have little to do when housed in a box stall. Fader and Sambraus (2004) reported that horses housed individually in a non-stimulating environment rest more often than those kept in stimulating group housing. This observation results in the necessity to consider the bedding materials differentiated according to the housing systems. The results of the present study indicate that horses kept in boxes with the opportunity to run around in an adjacent horse-pen with a sandy ground to lie on, significantly prefer wheat straw or wood shavings in the box as opposed to straw pellets. By carrying out the investigations in a freestall housing system and in a box stall housing system additional information could be gained regarding the acceptance of bedding materials. When horses are not given the alternative of the sandy horse-pen as a lying underground when being kept in a box stall, none of the used bedding materials either shortens or lengthens the total recumbency time of the horses. Thus, it may be concluded that all investigated bedding materials (provided misting out of the box is appropriate) can fundamentally be used in horse keeping, even if wheat straw or wood shavings are preferred to the use of straw pellets when regarding the lying behaviour.

\section{References}

Bachhausen I. (2008) Influence of different bedding materials on the behaviour of horses in box stall housing (Einfluss verschiedener Einstreumaterialien auf das Verhalten von Pferden in Boxenhaltung). Master thesis, Georg-August University Göttingen, Germany

Baumgartner M., Zeitler-Feicht M. H., Wöhr A.-C., Wöhling H., Erhard M. H. (2015) Lying behaviour of group-housed horses in different designed areas with rubber mats, shavings and sand bedding. Pferdeheilkunde 31, 211-220

BMELV, Bundesministerium für Ernährung, Landwirtschaft und Verbraucherschutz (publisher), Sachverständigengruppe tierschutzgerechte Pferdehaltung (2009) Guidelines on the assessment of horse husbandry systems under animal welfare aspects (Leitlinien zur Beurteilung von Pferdehaltungen unter Tierschutzgesichtspunkten).

Chaplin S. J., Gretgrix L. (2010) Effect of housing conditions on activity and lying behaviour of horses. Animal 4, 792-795

Crowell-Davis S. L. (1994) Daytime rest behavior of Welsh pony (Equus caballus) mare and foal. Appl. Anim. Behav. Sci. 40, 197-210

Daillaire A. (1986) Rest behaviour. Vet. Clin. North Am. Equine Pract. 2, 591-607

Fader C., Sambraus H. H. (2004) The resting behaviour of horses in open running barns (Das Ruheverhalten von Pferden in Offenlaufställen). Tierärztl. Umsch. 59, 320-327

Glade M. J. (1986) "Social Sleeping" among confined horses. J. Equine Vet. Sci. 6, 156-167

Hassenberg L. (2005) Behaviour in equidae (Verhalten bei Einhufern). Westarp Wissenschaften (publisher), Hohenwarsleben, Germany, 2nd edition, 4-118

Holm S. (1979) A simple sequentially rejective multiple test procedure. Scand. J. Stat. 6, 65-70 
Houpt K. A. (2005) Domestic animal behavior. Blackwell Publishing, Ames, USA, 96-97

Hunter L., Houpt K. A. (1989) Bedding material preferences of ponies. J. Anim. Sci. 67, 1986-1991

Kalus M. M.-C. N. L. B. (2014) Equine sleep behavior and physiology based on polysomnographic examinations (Schlafverhalten und Physiologie des Schlafes beim Pferd auf der Basis polysomnographischer Untersuchungen). Dissertation, Faculty of Veterinary Medicine of Ludwig-Maximilian University, Munich, Germany

Kiley-Worthington M. (1989, cited from Zeitler-Feicht, 2001): Equine psyche - horse behaviour - basics for riders, horse keepers and trainer (Pferdepsyche - Pferdeverhalten - Grundlagen für Reiter, Halter und Trainer), publisher Müller Rüschlikon, Zürich, Stuttgart, Wien

Korries O. C. (2003) Examination of the horse keeping in Lower Saxony: Valuation with regard to animal protection, while differentiating between different use and paying attention to health damages (Untersuchung pferdehaltender Betriebe in Niedersachsen: Bewertung unter dem Aspekt der Tiergerechtheit, bei Trennung in verschiedene Nutzungsgruppen und Beachtung haltungsbedingter Schäden). Dissertation, University of Veterinary Medicine Hannover, Germany

Kownaki M., Sas/mowski E., Budzynski W. (1978) Observations of the twenty-four hours rhythm of natura. Genetica Pol. 10, 61-77

Kunz D. (2006) Melatonin and sleep-wake regulation (Melatonin und Schlaf-Wach Regulation). Postdoctoral thesis, Medical Faculty of Charity, University Medical Center Berlin, Germany

Ninomiya S., Aoyama M., Ujiie Y., Kusunose R., Kuwano A. (2008) Effects of bedding material on the lying behaviour in stabled horses. J. Equine Sci. 19, 53-56

Petersen S., Tölle K. H., Blobel K. J., Krieter J. (2004) Evaluation of horse keeping in Schleswig-Holstein (Bewertung pferdehaltender Betriebe in Schleswig-Holstein). In: Symposium lecture meeting of the German Society for animal production and the German Society for Animal Science (Tagungsband Vortragstagung der Deutschen Gesellschaft für Züchtungskunde e.V. (DGfZ) und Gesellschaft für Tierzuchtwissenschaft (GfT)), 29th /30th of September 2004 in Rostock, Germany
Riemann Pedersen G., Søndergaard E., Ladewig J. (2004) The Influence of bedding on the time horses spend recumbent. J. Equine Vet. Sci. 24, 153-158

Schäfer M. (1993) The language of the horse (Die Sprache des Pferdes), publisher Franckh-Kosmos, Stuttgart, Germany, 63-72

Steinhart P. (1937) The sleep of the horse: its duration, depth, conditions (Der Schlaf des Pferdes: seine Daver, Tiefe, Bedingungen). Z. Veterinärk. 49, 193-232

Ubbejans M. (1981) Investigations on the keeping of riding horses on artificial floor coverings (Untersuchungen zur Haltung von Reitpferden auf künstlichen Bodenbelägen). In: Current aspects of ethology in horse keeping (Aktuelle Aspekte der Ethologie in der Pferdehaltung), FN publisher, Warendorf, Germany, 103-116

Werhahn H., Hessel E. F., van den Weghe H. F. A. (2009) Effect of different bedding materials on the behaviour of horses housed in single stalls (Einfluss verschiedener Einstreumaterialien auf das Verhalten von Pferden in Boxenhaltung). Landtechnik 64, 238-241

Wilcoxon F. (1945) Individual comparison by ranking methods. Biometrics Bull. 1, 80-83

Wöhr A.-C., Erhard M. (2006) Polysomnographic studies on the sleeping behaviour of the horse (Polysomnografische Untersuchungen zum Schlafverhalten des Pferdes). In: KTBL (ed.) Current activities on animal husbandry 2006 (Aktuelle Arbeiten zur artgemäßen Tierhaltung 2006), KTBL-scripture 448, Darmstadt, Germany, 127-135

Zeeb K. (1998) The nature of the horse (Die Natur des Pferdes), publisher Franckh-Kosmos, Stuttgart, Germany, 43-47

Zeitler-Feicht M. H. (2001) Handbook of Horse Behaviour (Handbuch Pferdeverhalten), publisher Eugen Ulmer KG, Stuttgart, Germany

Zeitler-Feicht M. (2013) The lying place of horses in terms to animal welfare (Der Liegebereich von Pferden unter dem Aspekt der Tiergerechtheit). Prakt. Tierarzt 94, 228-233

Zeitler-Feicht M., Muggenthaler K. (2013) To the lying behaviour of horses in group housing depending on the lying place layout and rank order (Zum Liegeverhalten von Pferden in Gruppenhaltung in Abhängigkeit von der Liegeplatzgestaltung und Rangordnung). Prakt. Tierarzt 94, 420-428 